This item was submitted to Loughborough's Research Repository by the author.

Items in Figshare are protected by copyright, with all rights reserved, unless otherwise indicated.

\title{
Economic geography and human rights
}

PLEASE CITE THE PUBLISHED VERSION

http://dx.doi.org/10.2139/ssrn.2458504

VERSION

SMUR (Submitted Manuscript Under Review)

\section{PUBLISHER STATEMENT}

This work is made available according to the conditions of the Creative Commons Attribution-NonCommercialNoDerivatives 4.0 International (CC BY-NC-ND 4.0) licence. Full details of this licence are available at: https://creativecommons.org/licenses/by-nc-nd/4.0/

LICENCE

CC BY-NC-ND 4.0

\section{REPOSITORY RECORD}

Edwards, T. Huw, Todd Landman, David Kernohan, and Azizun Nessa. 2019. "Economic Geography and Human Rights". figshare. https://hdl.handle.net/2134/15714. 


\title{
Economic Geography and Human Rights
}

\author{
Huw Edwards*, Todd Landman**, David Kernohan*** and AzizunNessa***
}

June, 2014

\begin{abstract}
This paper investigates the geo-political and international economic aspects of human rights performance using a pooled cross-section time-series data set. We start with simple descriptive accounts of the recent geographic history of human rights performance. We then test for basic economic effects of income and then apply tools from the spatial economics literature to examine the degree to which clusters of relative human rights performance exist. Using spatial weighting models we analyse the spatial impact of proximity and human rights performance of neghbours on overall levels of human rights performance. Unlike previous studies, our approach treats this spatial impact as partly endogenous: one country's human rights performance may affect its neighbours through a variety of potential geographical spillover mechanisms. The spatial weighting models take into account size and distance of neighbours in order to compare each country's human rights performance with what would be predicted by regression on a weighted average of its neighbours' performance. The findings sugest that there are (a) geographical clusters of human rights performance and (b) size and proximity effects for human rights performance, both of which have significant implications for the promotion and protection of human rights.
\end{abstract}

Keywords: Human rights, spatial econometrics

JEL Classifications: F59, P48, A12

*Loughborough University, UK.

** University of Essex, UK.

***Middlesex University, UK. 


\section{Introduction}

The observation of high standards of human rights protection has long been recognised as one of the distinguishing features of advanced societies. A clear difference exists between advanced nations and developing countries even when we differentiate between different catgegories of human rights, such as civil and political rights and economic and social rights. The extant cross-national and quantitative literature on human rights has looked either explicitly at socio-economic factors (e.g. Mitchell and McCormick 1988; Henderson 1993; Heinisch1998; Abouharb and Cingranelli 2007; Landman and Larizza 2009; Landman, Kernohan, and Gohdes 2012) or implicitly as control variables alongside different sets of social, political and cultural explanatory variables (e.g. Poe and Tate 1994; Poe, Tate and Keith1999). Model estimations in the literature also include controls for fixed effects or for regional and sub-regional variation typically as robustness checks (e.g. Landman 2005a; Landman and Larizza 2009). In this paper, we focus explicitly on the economic and geographical aspects of human rights performance with respect to physical integrity rights using a combined human rights factor score (see Landman and Larizza 2009; Landman, Kernohan and Gohdes 2012), regional dummy variables, and spatial weightings for both the size and proximity of neighbours.

In comparing trends in human rights performance across world regions over the past three decades it is evident that there are two broad 'clubs'. In 1980: one club consisted of Western Europe, North America and Oceania, and the other comprised the rest of the world. Between 1980 and 2004 the only major change is in the Central and Eastern European Countries, which move from the 'bad' convergence club to the 'good' (note some Latin American countries have also improved significantly). Our paper shows that these trends reflect both income and spatial factors. We find that the human rights factor score shows a clear relationship with levels of national income: ranking 149 countries in 2004 according to GDP per capita, 19 out of the top 20 countries are also in the top 30 in terms of human rights. At the other end of the table, however, while several out of the bottom 20 countries in terms of per capita GDP also rank badly for human rights - Congo, Burundi, Ethiopia, Chad, Nepal - it is also noticeable that Mali is 34th in terms of human rights, while Ghana, Burkina Faso and Guinea Bissau are in the top 60. 
To date, economists, with a few exceptions (Sykes, 2005), have paid relatively little attention to human rights as such. In this, economics lags behind the disciplines of law (Freeman, 2002) and political science (Landman, 2005b). However in recent years the field of international economics has become generally more concerned with socio-economic phenomena, such as the relative quality of national institutions (security, law, governance) in trade performance (Nunn, 2007a) and in particular in the role of social, institutional and political factors in growth (see Djankov et al, 2003; Acemoglu et al, 2008; Acemoglu and Johnson, 2005; Acemoglu, 2003; Nunn, 2007b, Tabellini, 2008 and 2010).

The role of human rights (other than property rights and the rule of law) to these crucial relationships in the developmental process is still, however, clouded in obscurity. Sala-iMartin (1997) does indicate a clear role for human rights-type variables in promoting economic growth. However, despite strong arguments (Acemoglu et al, 2004) that political institutions underlie the poverty traps besetting many countries, there has still been relatively little analysis of the role of human rights other than property rights in sustaining such traps. To some extent, this may reflect the influence of the 'institutional school' (Hayek, 1976 or Barro, 2000) arguing that human rights are somewhat irrelevant to the developmental process, where they are seen to be a 'good' which wealthier countries choose to supply to their population. Against this, we can set Sen's (1999) argument in favour of all types of human rights. For Sen, issues such as freedom, fairness and reciprocity are all of equal importance and social capital (which is assumed to encompass elements of both economic and noneconomic rights) has a positive effect on welfare and growth. Some tentative evidence in favour of Sen's argument has come from Blume and Voigt (2007), who found positive relationships between both property rights and non-economic human rights and development.

Just as economists have long recognised that certain poor countries (such as Sri Lanka and Cuba) have managed to provide relatively good healthcare and educational levels, we wish to analyse regional patterns in human rigthts, and the extent to which these vary for reasons other than simply income level differences. Are there perhaps beacon developing countries, ones that perform relatively well on human rights 'against the odds'?

In including not just poor regions, but regions where neighbouring countries have poor human rights records, such as the Middle East and North Africa, we are widening our definition of 
relative human rights to encompass location-related effects. Should certain countries, or country groups, deserve an element of credit for providing good human rights relative to their income level or relative to their neighbours?

In order to provide answers to these questions, the paper is structured into several sections. Section 2 discusses the database of human rights and other indicator before taking into account the spatial factors. Section 2.1 contains a brief discussion of the historical spread and regional patterns of human rights, in particular outlining the role of international human rights standards and treaties. Section 2.2 sets out some stylised facts and statistical tests suggestive that there may be significant economic and spatial relationships in human rights performane, and establishes some the broad trends within and between global regions. Section 3 outlines the full method for spatial econometric analysis. Section 3.1 discusses methodological issues relating to the data and the associated problems of estimation. Section 3.2 reports the results of the spatial econometric analysis and Section 4 concludes with a discussion of the implications of spatial spillovers identified in this paper.

\section{Data Description}

Much of our data come from Landman and Larizza (2009), who use a global data set comprised of 162 countries from 1980 and 2004. The data have been updated to for the period 1980 to 2010. The data set is comprised of variables for civil and personal integrity rights protection, income and land inequality, and a series of additional variables.The protection of civil and personal integrity rights is operationalised using five "standards-based" (Jabine and Claude 1992) human rights scales: (1) the Amnesty International version of the Political Terror Scale, (2) the US State Department version of the Political Terror Scale, (3) the Cingranelli and Richards Index of Personal Integrity Rights (based on the US State Department www.humanrightsdata.com), (4) the Freedom House civil liberties scale (base on various sourdes), and (5) Hathaway's (2002) scale of torture (also based on the US State Department). In following Landman and Larizza (2009) we created human rights factor score based on principal components extraction and then inverted the resulting index to make it more intelligible. Low values of the factor score correspond to a low protection of human rights (high violations) and high values correspond to a high protection of human rights (low violations). This variable is approximately normally distributed, with a mean by definition of 
0 , a minimum value is -2.7 and a maximum value is 1.97 .

Our selection of other explanatory variables includes income inequality, land inequality, domestic conflict, real per capita income and regional and cultural dummy variables (see Landman and Larizza 2009). This collection of variables represents those that have received the most support or generated the most consensus within the cross-national quantitative research on human rights (see Landman 2005a, 2006a, 2009b for a summary). Each of these variables and the ways in which they are operationalized are discussed in turn.

For income inequality, we use a measure based on the "inequality project” (UTIP) (Galbraith and Kum 2004) which now covers a large panel of countries from 1980 to 2010. This new dataset provides comparable and consistent measurements across space and through time, thus being a more valid proxy of income inequality than the Deininger and Squire data usually employed by cross-national empirical studies (Galbraith and Kum 2004). For our estimations, a linear interpolation of the original EHII variable has been computed for each country-series to increase the number of observations.

For land inequality, we use a measure that is expressed as the area of family farms as a percentage of the total area of land holdings (Vanhanen 1997). The reasoning behind this measure is that the higher the percentage of family farms, the more widely economic power resources based on ownership patterns of agricultural land are distributed (Vanhanen 1997: 47). Family farms are defined as "holdings that are mainly cultivated by the holder family and that are owned by the cultivator family or held in ownerlike possession" (Vanhanen 1997: 49). The data on landownership were mainly derived from the FAO World Censuses of Agriculture (from the 1960s to the 1980s) and Vananhen's own estimations for the 1990s. As with our income inequality data, these data have been interpolated to fill in missing time points for those countries where two or more time points of data were made available. To make this variable equivalent to income inequality in terms of its measurement of land inequality, it has been inverted by subtracting the original percentage value from 100 such that a low score means a more favorable distribution of land.

As in the research on human rights and political violence, we include a variable for internal domestic conflict, which is specified as an independent variable alongside the other variables in our model. We do not use the simple dummy variable for civil war from the Correlates of War project as in much of extant work on human rights, nor do we use events-based 
measures of the kind coded from single and multiple news sources found in the literature on political violence. The civil war dummy is still a fairly crude variable that tends to absorb quite a lot of the explanatory space in most human rights literature (see Poe and Tate 1994) and the events-based measures have proved to be fairly insecure for the kind of cross-national and time-series comparisons conducted here on grounds of validity and reliability. We thus employ the International Country Risk Guide (ICRG) measure of internal conflict, which is an aggregate 12-point scale that comprises the overall risk levels for civil war and threat of a military coup, terrorism and political violence, and general levels of civil disorder. We feel that this measure is superior in some respects since it provides greater variance than the civil war dummy and perhaps greater validity than the event-based measures of conflict to date.

The level of economic development is measured through the natural log of the value of real per capita income (GDP, constant 2005 US\$) and is taken from the World Bank Development Indicators. Total population size is based on de facto definition of population, which counts all residents regardless of legal status or citizenship - except for refugees not permanently settled in the country of asylum, which are generally considered part of the population of their country of origin. The variable is also taken from the World Bank.

\subsection{Regional patterns of HR}

As a simple introductory procedure to check on the plausibility of our analysis, in Figures 1-6 (see Appendix 1) we present some descriptive statistics of the geographic history of human rights performance, which suggest that regional levels of human rigthts can change significantly in relative terms over time. In Figures 1 and 2 we can see that human rights in the commonwealth of independent states (CIS) actually worsened on average after the downfall of the Soviet Union. Human rights also worsened in the MEAST and Sub-Saharan Africa (SSA) which can be noted in Figures 3-4 (see Appendix 1).

Figure 6 (see Appendix) shows the trends in regional HR averages over the 30-year period, as well as intra-regional variations. Comparing means of the various regions shows that there appear to be two 'clubs' in 1980: the one consisting of Western Europe/ North America and Oceania, and the other containing the Rest of the World. Between 1980 and 2010 the only major real change is the Central and Eastern European Countries (CEECs), which move from 
the 'bad' convergence club to the 'good'. Latin America has shown a modest improvement, reflecting the fall of dictatorships and military authoritarian regimes, while the Middle East/North Africa, Asia and the CIS countries have actually worsened, particularly in the period to the mid 90s (with some recovery since).

Although not presented here, in our graphical analysis we found strong positive correlations between human rights and per capita GDP. There is strong evidence that richer countries supply their citizens with better rights (see, e.g. Mitchel and McCormick 1988; Poe and Tate 1994; Poe, Tate and Keith 1999; Landman and Larizza 2009; Landman, Kernohan and Gohdes 2012), but at the same time some weaker evidence that human rights benefit economic growth (Blume and Voight, 2007; see also Norris 2012). Although we found a lack of any clear relationship between changes in human rights against the changes in GDP, this may indicate that the relationship between GDP and human rights is a long-term one, not short-term in keeping with the social capital argument favoured by Sen.

\subsection{Human Rights and Socio-economic Factors}

In order to examine these issues further, we regress the levels of human rights performance across three time periods, (1980-89), (1990-99) and (2000-09) on a series of regional dummies. The results can be seen in Table-1 (see Appendix 2). We dropped the dummy for Western Europe/North America (WENA), such that the regressions compare all other regions with this advanced set of countries. Consequently, the constant (which actually decreases between the earlier and later periods) represents the average level for WENA countries, while other values represent the difference from WENA.

The first thing to note is that regional dummies are all significant, with the Middle East (MEAST) and Asia showing particularly poor performance. We note a change in sign on the CEEC coefficient, which implies that regions can also change performance significantly in relative terms. In fact, the CEECs did improve markedly in this respect between 1980-89 and 2000-09. There estimates change from negative for the period 1980-1989 to positive in the two latter periods, which is in line with expectations given their transition away from authoritarianism after 1989. 
Since the regional dummies were all significant, we then regressed levels of human rights performance on a number of socio-economic variables along with the regional dummies which increased the overall goodness of fit: hence the final model in Table 2 (see Appendix 2) explains $54 \%$ of the variation in human rights performance (as opposed to the $12 \%$ to $17 \%$ shown in Table 1). The coefficients of the explanatory variables in the non-spatial model are significantly different from zero and have the expected signs: the level of human rights is positively related to the level of income (income elasticity 0.1814 ) and negatively correlated with inequality (income and land) and conflict.

Although we have succeeded in identifying regional differences in levels of human rights performance in these non-spatial regressions, the spatial dependence observed above may not reflect a truly spatial process but merely the geographic clustering of the sources of the behaviour in question as neighboring countries have shared or similar attributes.

What we are trying to capture is a country's human rights performance relative to its neighbours, which may arise through a variety of potential geographical spillover mechanisms. Hence, the following section focuses on a method for determining how human rights vary spatially.

\section{Establishing Spatial Effects}

Since a country's relative human rights performance may arise through a variety of potential geographical spillover mechanisms, the spatial dependence observed above may not reflect a truly spatial process but merely the geographic clustering of the sources of the behaviour in question as neighboring units share attributes. In order to capture a country's true human rights performance relative to its neighbours, we need to establish a spatial effect.

First of all, a regional pattern may reflect common causal factors, which happen to be concentrated in certain global regions. For example, in the case of property rights and the rule of law, Acemoglu et al (2004) argue that different patterns of colonisation have resulted in very different patterns: in those areas which European colonists found relatively empty, they instituted property laws and institutions which favoured fairly equitably the rights of all the new settlers, whereas where there was an existing large population and/or a valuable resource base to exploit, institutions were put in place which favoured the colonists at the expense of 
the indigenous (or imported slave) population. Nunn's (2007b) work on the role of slavery in determining bad institutions in Africa is in this same tradition. There are good reasons to believe that persistence of bad institutions may also apply in the case of human rights.

Countries in a region can also share a common culture, which may be more or less favourable to human rights (or interpret them in different ways to Western compilers of human rights indices). Alternatively, there maybe common causes in the sense of regional security crises. There may be rebellions by cross-border ethnic groups, such as the Kurds in Turkey and Northern Iraq. Civil wars may spread across borders (for example, the displacement of the Rwandan crisis in the 1990s to neighbouring Congo). Moreover, even though economic activity, such as GDP per capita, can have spatial patterns, we can correct for this by including GDP per capita in any spatial regressions. When we estimate the effect on human rights in one country on the human rights of its neighbours, then any spillover in GDP can be controlled in our estimations.

The alternative explanation of spatial patterns is that there are direct spillovers between the human rights performance in one country to its neighbours, which can be direct (e.g. as a reflection of colonisation or occupation), or indirectly through, for example, treaties and issue-linkages in trade negotiations (such as in the case of the European Union). Alternatively, private investors may react to differences in observed human rights in other countries, which may have selfish rationale, since a country that behaves well in terms of human rights may well be signalling responsible governance in other areas.

Beyond this, there is plenty of evidence of demonstration effects, as can be seen in Latin America in the1980s/90s or the Middle East/North Africa today. A country which liberalises its political and legal system with no adverse effects (or maybe with benefit) is likely to have a positive influence upon other countries. We would expect this effect to be stronger, the closer the ties between countries' citizens, and the greater the similarities between the countries. In this way, there may a 'gravity' type spatial spill over mechanism, since a country which is large and nearby will have more effect on its neighbours. These types of spillover effects and processes of spatial diffusion are modelled and estimated in the next section. 


\subsection{Modelling Strategy}

Our modelling strategy first looks at economy/human rights relationships, then at the issue of spatial clusters of human rights performance (analogous to performance on standard measures of socio-economic progress), and then at gravity or neighbourhood effects in the spirit of international trade linkages, which demonstrate the importance of proximity. We develop a formal spatial econometric model based upon a panel of 91 countries between 1992 and 2010 (the remaining countries and years had to be excluded as some of the data were incomplete). A critical assumption here is that changes in one country's human rights performance may be correlated with performance in other countries, where the degree of correlation depends on the distance between the two countries. Such an assumption is common in spatial econometrics (see Arbia et al, 2010).

Spatial econometric models treat cross-border spillovers as a form of autocorrelation (in terms of distance rather than autocorrelation over time), where Moran's I statistic and the Local Indicator for Spatial Autocorrelation (LISA) are used to check the global and local autocorrelation, respectively. The Moran's I statistic is given by the following expression:

$$
I_{G}=\frac{\sum_{i} \sum_{j} w_{i j} z_{i} z_{j}}{\sum_{i} z_{i}^{2}}
$$

Figure 7 (see Appendix 3), reports the results of Moran’s I statistic for HR in 1992, regardless of the spatial structure imposed, and this variable shows a positive association between the original variable and its spatially lagged version. Figure 7 clearly indicates that human rights performance should not be viewed as a randomly distributed variable, but rather as one that has systematic spatial attributes. The spatial autocorelation for human rights is 0.3105 using our speicificaiton of the the inverse of the squared distance and the population weighted measure of autocorrelation is 0.3114 . This spatial autocorrelation suggests that countries with good human rights performance are more likely to be close to each other. If this spatial dependence is reflected in the error term, regression results using standard econometric estimators, which ignore spatial dependence, will prove unreliable. We, therefore, use a spatial extension of the linear regression model. 
As pointed out by Anselin, Gallo, and Jayet (2008), a spatial panel data model may contain a spatially lagged dependent variable (spatial lag model) or the model may incorporate a spatially autoregressive process in the error term (spatial error model) A third model, advocated by LeSage and Pace (2009), contains a spatially lagged dependent variable and spatially lagged independent variables (spatial Durbin model). We applied spatial lag model as our main interest is to understand whether or not neighbourhood effects exist in a given country's achievement of relative progress in human rights. Formally, the spatial lag model is formulated as

$$
Y_{i t}=\delta \sum_{J=1}^{n} W_{i j} Y_{j t}+\alpha+X_{i t} \beta+\mu_{i}+\gamma_{t}+\varepsilon_{i t}
$$

where $Y_{i t}$ is the dependent variable for cross-sectional unit $\mathrm{i}$ at time $\mathrm{t}(\mathrm{i}=1, \ldots \mathrm{N} ; \mathrm{t}=1, \ldots . ., \mathrm{T})$. $\sum_{j} W_{i j} Y_{j t}$ stands for the interaction effect of the dependent variable $Y_{i t}$ with the dependent variables $Y_{j t}$ in neighboring units, where $W_{i j}$ is the i,j-th element of a pre-specified nonnegative $N^{*} N$ spatial weights matrix $W$ describing the arrangement of the spatial units in the sample. $X_{i t}$ a $1 * \mathrm{~K}$ vector of exogenous variables, and $\beta$ a $\mathrm{K}^{*} 1$ vector of fixed but unknown parameters. $\varepsilon_{i t}$ is an independently and identically distributed error term for $\mathrm{i}$ and $\mathrm{t}$ with zero mean and constant variance. $\mu_{i}$ denotes a spatial specific effect which control for all space-specific time-invariant variables whose omission could bias the estimates in a typical cross-sectional study. $\gamma_{t}$ denotes a time-period specific effect which control for all time-specific effects whose omission could bias the estimates in a typical time-series study (Baltagi 2005). If $\mu_{i}$ and/or $\gamma_{t}$ are treated as fixed effects, the intercept $\alpha$ can only be estimated under the condition/conditions that $\sum_{i} \mu_{i}=0$ and $\sum_{t} \gamma_{t}=0$. An alternative and equivalent formulation is to drop the intercept from the model and to abandon one of these two restrictions (see Hsiao 2003, 33). We followed the latter in our estimation. We also adopted the bias correction procedure proposed by Lee and Yu (2010a). However such bias correction will have hardly had any effect if T is large (Elhorst, 2012).

Now one potential spatial weight matrix is expressed as the inverse of the squared distance between each pair of countries to account for the intuition that a given country is more related to those countries that are closer: 


$$
\begin{aligned}
& W=w_{i j}=0 \text { if } i=j, \\
& W=w_{i j}=\frac{1}{d^{2}} \text { if } i \neq j
\end{aligned}
$$

Where $W$ is the spatial weight and $d_{i j}$ denotes the geographical distance betweenany two countries $i$ and $j$. In addition to distance, simple spatial weighting can also be done according to population size, where it is likely that countries with larger population have a greater impact on neighbouring countries:

$$
\begin{aligned}
& W=w_{i j}=0 \text { if } i=j, \\
& W=w_{i j}=\frac{1}{d^{2}} \times \frac{\text { Pop }_{j}}{\text { Pop }_{i}} \text { if } i \neq j
\end{aligned}
$$

Here, the spatial weight $W$ is a function of the inverse squared distance between country $i$ and $j$, as well as the ratio of the population of country $j$ to the population of country $i$. It is also possible to use a weighting scheme based on GDP (as in gravity modelling of trade); however, the main problem with this is that GDP may not be entirely exogenous, which could cause estimation biases in a spatial econometric model.

\subsection{Results from Spatial Regressions}

As demonstrated in Anselin (1988), OLS might produce biased results when there is a spatially autocorrelated dependent variable and he proposed the maximum likelihood (ML) estimator to produce reliable estimators. We used Anselin's ML estimator to perform the regressions in cross-section and its extension proposed by Elhorst (2010) for panel estimates. As is standard in panel econometrics, models can be estimated either using random effects, fixed effects or an amalgam of both estimators (random coefficients modelling). One important thing to note here is that although it is tempting to compare the coefficient estimates in the non-spatial model with their counterparts in the spatial model, any such comparison would not be valid (see Elhorst, 2010). However the parameter estimates in the non-spatial model can be seen as representing the marginal effect of a change in the income level on level of human rights (see Section 2.2), the coefficients in the spatial model do not.

We first present the results of panel regressions without fixed effects in Table-3 (see 
Appendix 4), where the first two regressions use the distance-only weighting scheme, while the next two use a population-based weighting. The effect of per capita GDP on human rights is significant and positive. Both measures of inequality are found to be significantly and negatively correlated with human rights. Domestic conflict is also found to exert a significant negative effect, as expected.

The variable $\mathrm{W}^{*}$ dep.var denotes the interaction effect of the level of human rights in a country with the level of human rights in neighbouring countries. The significant and positive spatial coefficients on the $\mathrm{W}^{*}$ dep.var variable (see column 1 and 3 of Table-3) establishes that a neighbourhood effect exists. Hence, it would appear that 'beacon countries' can play an important role in disseminating good human rights practice to neighbours, and by extension, from the same result, that rogue countries can potentially destabilize (even) virtuous neighbours.

In the model without fixed effects it is possible to include cultural or other variables, which may be largely invariant over time (see column 2 and 4 of Table-3). This is important, since the inclusion of these variables may help us interpret the degree to which our estimated spatial weightings are picking up regionally-varying historical or cultural factors: for this reason, we include variables for Catholic culture and the proportion of Muslims in the regression equation. Inclusion of these variables has slightly reduced the power of the spatial weighting (compare column 1, 2 and column 3, 4 of Table-3), but it is still positive and significant and we can say that there are indeed regional spillovers, in addition to some spatially-varying cultural factors present.

Our results seem robust since most of the estimated coefficients are little affected by the choice of i) distance-only weighting ('weighting 1') and distance and populationbased weighting, 'weighting 2'), with the exception of the spatially-weighted dependent variable ( $\mathrm{W}^{*}$ dep.var), which clearly does have a stronger estimated effect once population is included. The estimated coefficient of $\mathrm{W}^{*}$ dep.var is higher when we applied distance and population-based weighting ('weighting 2') instead of a distanceonly weighting ('weighting 1'). This larger coefficient of 0.3020 on the 'weighting 2' as opposed to 0.2169 on 'weighting 1' observed in column 2 and 4 of Table-3 suggests that a large neighbour has more influence on a country's level of human rights than a smaller neighbour. 
Table-4 (see Appendix 4) presents the results of panel regressions with fixed effects. The Lagrange multiplier (LM) test indicates that the fixed effect is supported, in preference to a random effects specification. Panel regression with fixed effects performs better in terms of fit. As before, all the control variables have the correct sign and significance. We can see that the spatial coefficient is little changed comapared to that obtained in the regressions without fixed effect. The positive and significant spatial coefficient implies that the spatial model is to be preferred to a non-spatial model. Table-4 reinforces our two main findings (1) beacon countries' can play an important role in disseminating good human rights practice to neighbours (2) a large neighbour has more influence on a country's level of human rights than a smaller neighbour.

While in general there is not much to chose between the two spatial-econometric weighting specifications, the encouraging aspect of our results is that not only economic and socioeconomic aspects within a country, but also its geographic position can alter its ability to raise standards of HR relative to international norms and standards.

\section{Summary/Conclusions}

In recent years, social scientists have turned their attention not only to the importance of institutional factors in achieving economic and political progres, but also to the frequently long-run relationships that exist between socio-economic variables that can be hard to detect without careful measurement techniques (e.g Acemoglu et al., 2004). Central to these endeavours has been the idea of quantifying institutional and cultural variables, and the need for data sets covering a wide variety of countries over longer periods of time.

Here we turn our attention to the possibility not only of relative effects in human rights performance, but also whether neighbourhood effects might exist in a given country's achievement of relative progress in human rights. This is not without its technical difficulties, because of the wide variety of countries involved and the frequently long-run nature of the relationships described.

We introduce a comprehensive index of human rights developed by Landman and Larizza (2009), and drawing on a number of other studies build empirical models that estimate spatial dimensions of human rights performance. Using a relatively simple spatial weighting model 
we compare each country's human rights performance with what would be predicted by regression on a weighted average of its neighbours' performance. The results of our analusis confirm earlier findings (Landman and Larizza, 2009) that human rights performance appears to be linked to other socioeconomic variables, although we find that this relationship is limited in terms of income/GDP and is probably only robust in the longer term. While (lagged) GDP per capita may be suggestive that causation is primarily from income to human rights, we cannot rule out bi-directional causality. However, we also find that clear regional patterns are apparent in HR performance, which appear to go beyond what can be explained by GDP patterns alone. This is picked up either by including regional dummies, as well as by more the more explicit use of spatial econometric estimation techniques. The inclusion of simple cultural variables only mildly reduces the significance of the spatial terms, indicating that (within a country) there may be an interaction effect between the pure economic and the (somewhat arbitrary) geographic mechanisms involved.

Notwithstanding the recent history of democratic spread across broad groups of countries, such as the Former Soviet Bloc, parts of Latin America or most recently possibly North Africa, we believe that this is the first study to overtly disentangle the economic from the geographic factors involved. Further our analysis may suggest that 'beacon countries' can play an important role in disseminating good human righs practice to neighbours.

Such findings may have policy significance. In terms of relative human rights performance, regional good performers may play a part in promoting incremental progress in HR in the world's poorer or more troubled regions. If, as it is sometimes implicitly argued, it is economically costly to rely primarily on formal law to promote convergence with international HR norms, convergence may nonetheless occur via indirect social norms, via the proximity to good neighbours. 


\section{References}

[1] Abouharb, M.R. and Cingranelli, D.L. (2007) Human Rights and Structural Adjustment, Cambridge: Cambridge University Press.

[2] Abreu M, de Groot H, Florax R (2005) Space and Growth: A Survey of Empirical Evidenceand Methods. Région et Développement 21:13-44.

[3] Acemoglu, Daron, 2003. "Why not a political Coase theorem? Social conflict, commitment, and politics," Journal of Comparative Economics, Elsevier, vol. 31(4), pages 620-652, December.

[4] Acemoglu, D., S.Johnson and J.Robinson (2004): "Institutions as the Fundamental Cause of LongRunGrowth", NBER Working Paper 10481, National Bureau of Economic Research.

[5] Acemoglu, D. \& Simon Johnson, 2005. "Unbundling Institutions," Journal of Political Economy, University of Chicago Press, vol. 113(5), pages 949-995, October.

[6] Acemoglu, D. \& Simon Johnson \& James A. Robinson \& Pierre Yared, 2008. "Income and Democracy," American Economic Review, American Economic Association, vol. 98(3), pages 808-42, June.

[7] Anselin, Luc, 1988. "A test for spatial autocorrelation in seemingly unrelated regressions," Economics Letters, Elsevier, vol. 28(4), pages 335-341.

[8] Anselin, Luc \& Bera, Anil K. \& Florax, Raymond \& Yoon, Mann J., 1996. "Simple diagnostic tests for spatial dependence," Regional Science and Urban Economics, Elsevier, vol. 26(1), pages 77-104, February.

[9]Arbia,Giuseppe\&Battisti,Michele\&DiVaio,Gianfranco,2010."Institutionsandgeography:Empiricaltes tofspatialgrowthmodelsforEuropeanregions,"EconomicModelling,Elsevier,vol.27(1),pages12-

21,January.

[10]Barro,R.J.(2000).RuleofLaw,Democracy,andEconomicPerformance,In2000IndexofEconomicFreedo m.Washington,D.C.:TheHeritageFoundation:31-49.

[11]Blume,L.andS.Voigt,2007.“TheEconomicEffectsofHumanRights”,Kyklos,Vol.60-2007-No.4,509_ 538.

[12] P Burridge, 1981. "Testing for a common factor in a spatial autoregression model," Environment and Planning A, Pion Ltd, London, vol. 13(7), pages 795-800, July.

[13] Cingranelli, David and Richards, David. 1999. "Measuring the Level, Pattern, and Sequence of Government Respect for Physical Integrity Rights.” International Studies Quarterly. 43 (2): 407-418.

[14] Djankov, Simeon \& Glaeser, Edward \& La Porta, Rafael \& Lopez-de-Silanes, Florencio \& Shleifer,Andrei, 2003. "The new comparative economics," Journal of Comparative Economics, Elsevier, vol.31(4), pages 595-619, December.

[15] Elhorst,J.Paul, 2010. "Applied Spatial Econometrics: Raising the Bar," Spatial Economic Analysis, Taylor and Francis Journals, vol. 5(1), pages 9-28.

[16] Foweraker, Joe and Landman, Todd. 1997. Citizenship Rights and Social Movements: A Comparative and Statistical Analysis. Oxford: Oxford University Press.

[17] Freeman, M. (2002) Human Rights: An Interdisciplinary Approach, Cambridge, UK and Malden, MA: Polity.

[18] Hathaway, Oona. 2002. "Do Treaties Make a Difference? Human Rights Treaties and the Problem of Compliance.” Yale Law Journal. 111: 1932-2042.[19]Hayek,F.(1976).Law, Legislation and Liberty, Vol.2,TheMirageofSocialJustice.Chicago:UniversityofChicagoPress. 
[20] Heinisch, R. (1998) 'The Economic Nature of Basic Human Rights: Economic Explanations of CrossNational Variations in Governmental Basic Human Rights Performance,’ Peace and Change, 23 (3): 333-372.

[21] Henderson, C. (1991) 'Conditions Affecting the Use of Political Repression', Journal of Conflict Resolution, 35 (1): 120-142.

[22] Jabine, Thomas B. and Claude, Richard P., eds. 1992. Human Rights and Statistics: Getting the Record Straight. Philadelphia: University of Pennsylvania Press.

[23]Landman,Todd.(2005a).“ReviewArticle:ThePoliticalScienceofHumanRights.”British JournalofPoliticalScience35(3):549-572.

[24] Landman, Todd. 2005b. Protecting Human Rights: A Comparative Study, Washington DC: Georgetown University Press.

[25] Todd Landman, David Kernohan and Anita Gohdes (2012) 'Relativising Human Rights,' Journal of Human Rights, 11:4, 460-485.

[26]Landman,T.andM.Larizza(2009):InequalityandHumanRights:WhoControlsWhat, When,andHow.Int ernationalStudiesQuarterly(2009)53,715-736.

[27] Mitchell N.J. and McCormick, J.M. (1988) 'Economic and Political Explanations of Human Rights Violations', World Politics, 40:476-498.

[28]NathanNunn,2007."Relationship-Specificity,IncompleteContracts,andthePatternofTrade,"The QuarterlyJournalofEconomics,MITPress,vol.122(2),pages569-600,05.

[29]Nunn,Nathan,2007."Historicallegacies:AmodellinkingAfrica’spasttoitscurrentunderdevelopment,"Jo urnalofDevelopmentEconomics,Elsevier,vol.83(1),pages157-175,May.

[30] Poe, Steven and Tate, Neal. 1994. "Repression of Human Rights to Personal Integrity in the 1980s: A Global Analysis.” American Political Science Review. 88 (4): 853-872.

[31] Poe, S.C., Tate, C.N. and Keith, L.C. (1999) 'Repression of the Human Right to Personal Integrity Revisited: A Global Cross-national Study Covering the Years 1976-1993', International Studies Quarterly, 43:291-313

[32]Sala-i-

Martin,Xavier,1997."IJustRanTwoMillionRegressions,"AmericanEconomicReview,AmericanEconomic Association,vol.87(2),pages178-83,May.

[33]Sen,A.(1999). DevelopmentasFreedom.Oxford:OUP.

[34]InternationalTradeandHumanRights:AnEconomicPerspective,inTradeandHuman[29] Sykes, A.O. (2005): Rights: Foundations and Conceptual Issues, Frederick M. Abbott, ChristineBreiningKaufmann and Thomas Cottier eds. (University of Michigan Press 2005).

[35] Tabellini, Guido, 2008. "Presidential Address Institutions and Culture," Journal of the European Economic Association, MIT Press, vol. 6(2-3), pages 255-294, 04-05.

[36] Tabellini, Guido, 2010.Culture and Institutions: Economic Development in the Regions of Europe, Journal of the European Economic Association, 8(4) 677-716. 


\section{Appendix 1}

Fig-1

ihrfactor over the period 1980-2010(CIS)

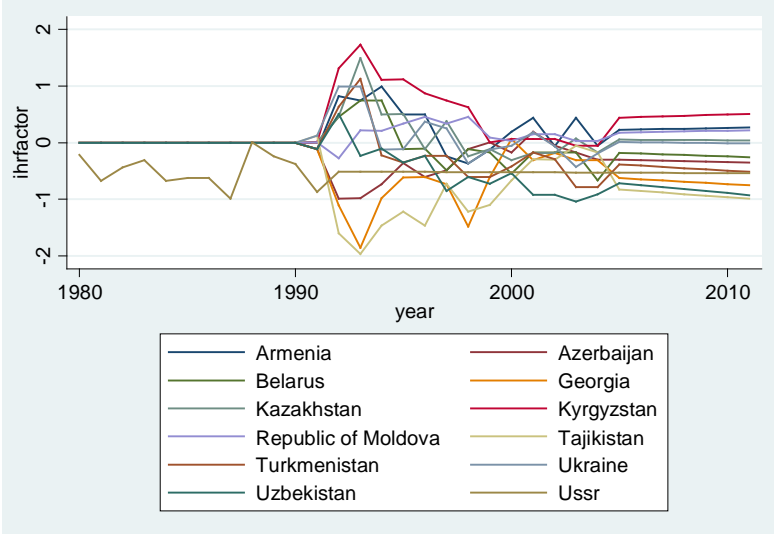

Fig-3

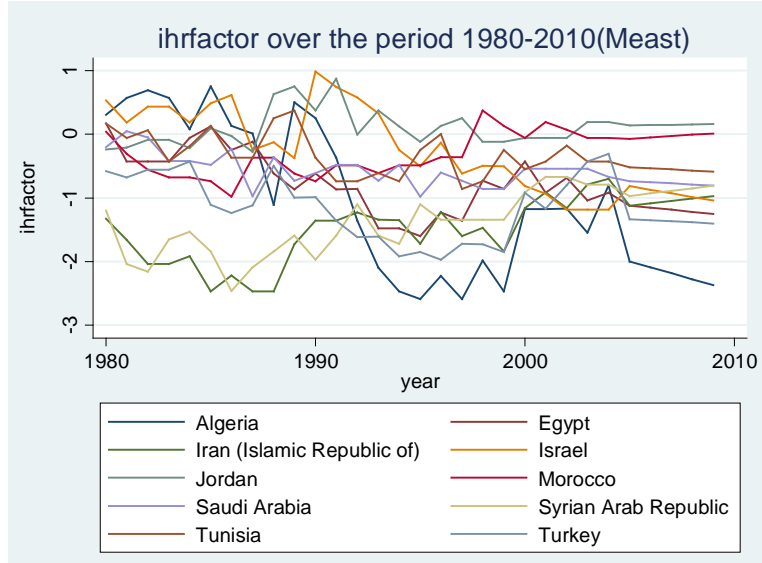

Fig-5

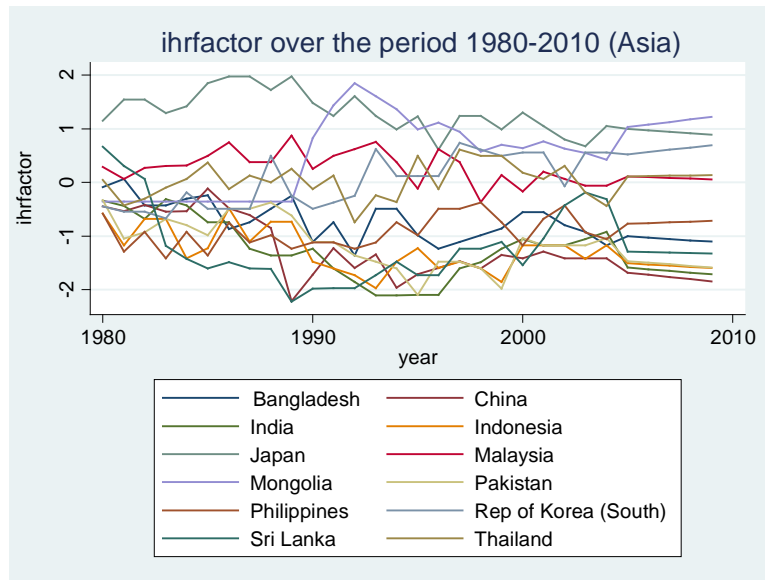

Fig-2

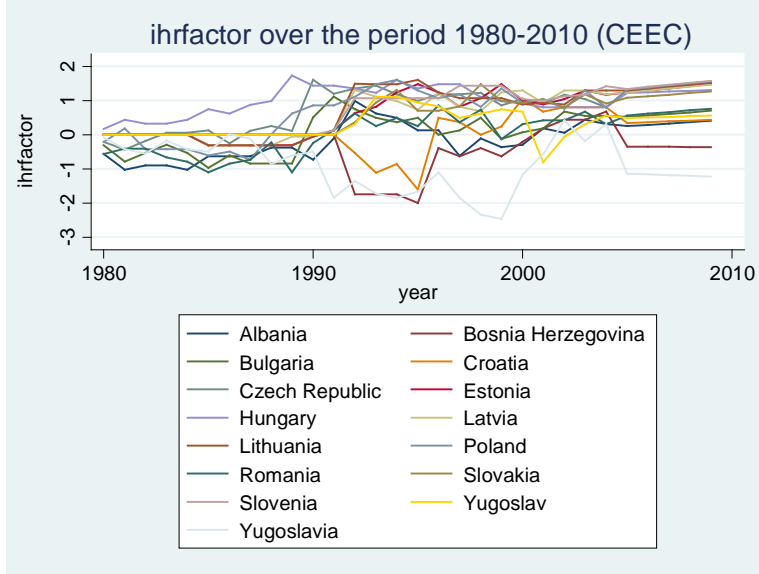

Fig-4

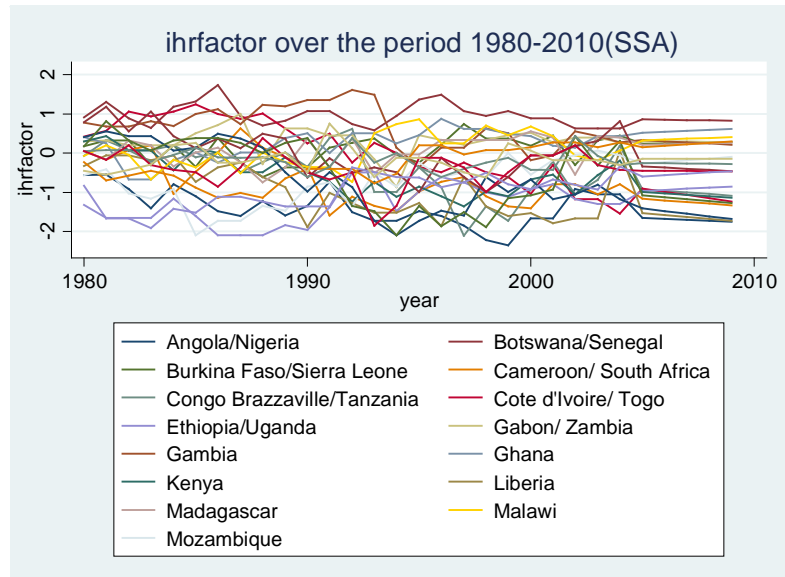

Fig-6

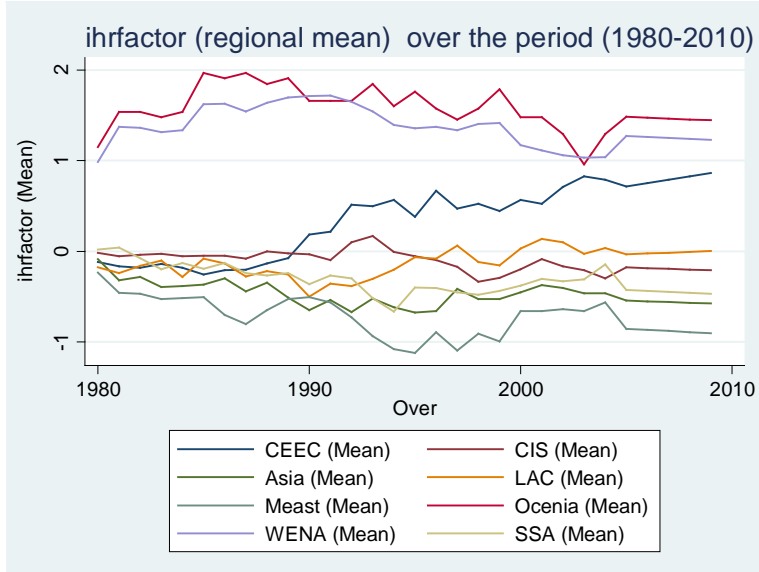




\section{Appendix 2}

Table-1: Regional differences in HR performance (1980-2009)

\begin{tabular}{lccc}
\hline Ihrfactor & $\mathbf{1 9 8 0 - 8 9}$ & $\mathbf{1 9 9 0 - 9 9}$ & $\mathbf{2 0 0 0 - 0 9}$ \\
\hline Ssa & $-0.4378^{* * *}$ & $-0.6472^{* * *}$ & $-0.4990^{* * *}$ \\
Asia & $-0.6392^{* * *}$ & $-0.7995^{* * *}$ & $-0.6257^{* * *}$ \\
ceec & $-0.4626^{* * *}$ & $0.2270^{* * *}$ & $0.6064^{* * *}$ \\
Cis & $-0.3359^{* * *}$ & $-0.3361^{* * *}$ & $-0.3706^{* * *}$ \\
Lac & $-0.4884^{* * *}$ & $-0.4297 * * *$ & $-0.1089^{*}$ \\
meast & $-0.8348^{* * *}$ & $-1.1019 * * *$ & $-0.8882^{* * *}$ \\
oceania & $1.3894 * * *$ & $1.4397 * * *$ & $1.2533^{* * *}$ \\
cons & $0.2960^{* * *}$ & $0.2196 * * *$ & $0.1295^{* * *}$ \\
\hline $\mathrm{N}$ & 1630 & 1630 & 1630 \\
rsquared & 0.1237 & 0.1390 & 0.1752 \\
\hline$*=$ significant at 10\% level & & \\
$* *=$ significant at $5 \%$ level & & \\
$* * *=$ signifiacant at $1 \%$ level & & \\
\hline
\end{tabular}

Table 2: Non-spatial regressions for human rights (1980-2010)

\begin{tabular}{|c|c|c|c|c|c|c|}
\hline ihrfactor & Reg1 & Reg2 & Reg3 & Reg4 & Reg5 & Reg6 \\
\hline _cons & $-2.7230 * * *$ & $1.9381 * * *$ & $0.7183^{* * *}$ & $0.7231^{* * *}$ & $-0.1654 * * *$ & $-0.1430 * * *$ \\
\hline lnpcgdp & $0.3555^{* * *}$ & & & & $0.1845^{* * *}$ & $0.1814^{* * *}$ \\
\hline lincineq & & $-0.0450 * * *$ & & & $-0.0100 * * *$ & $-0.0067 * * *$ \\
\hline llandineq & & & $-0.0136 * * *$ & & $-0.0056 * * *$ & $-0.0062 * * *$ \\
\hline domconflict & & & & $-0.2143 * * *$ & $-0.1457 * * *$ & $-0.1378 * * *$ \\
\hline ssafrica & & & & & & $-0.0641^{*}$ \\
\hline Asia & & & & & & $-0.5949 * * *$ \\
\hline Ceec & & & & & & -0.0039 \\
\hline Cis & & & & & & $-0.0816^{*}$ \\
\hline lamerica & & & & & & $-0.1202 * * *$ \\
\hline meast & & & & & & $-0.8780 * * *$ \\
\hline oceania & & & & & & $0.4376 * * *$ \\
\hline $\mathrm{N}$ & 4408 & 5053 & 5053 & 5053 & 4408 & 4408 \\
\hline R-squared & 0.3368 & 0.1135 & 0.0827 & 0.3382 & 0.4717 & 0.5411 \\
\hline $\begin{array}{l}*=\text { significan } \\
* *=\text { significa } \\
* * *=\text { signifia }\end{array}$ & $\begin{array}{l}10 \% \text { level } \\
\text { t } 5 \% \text { level } \\
\text { t at } 1 \% \text { level }\end{array}$ & & & & & \\
\hline
\end{tabular}




\section{Appendix 3}

Fig-7
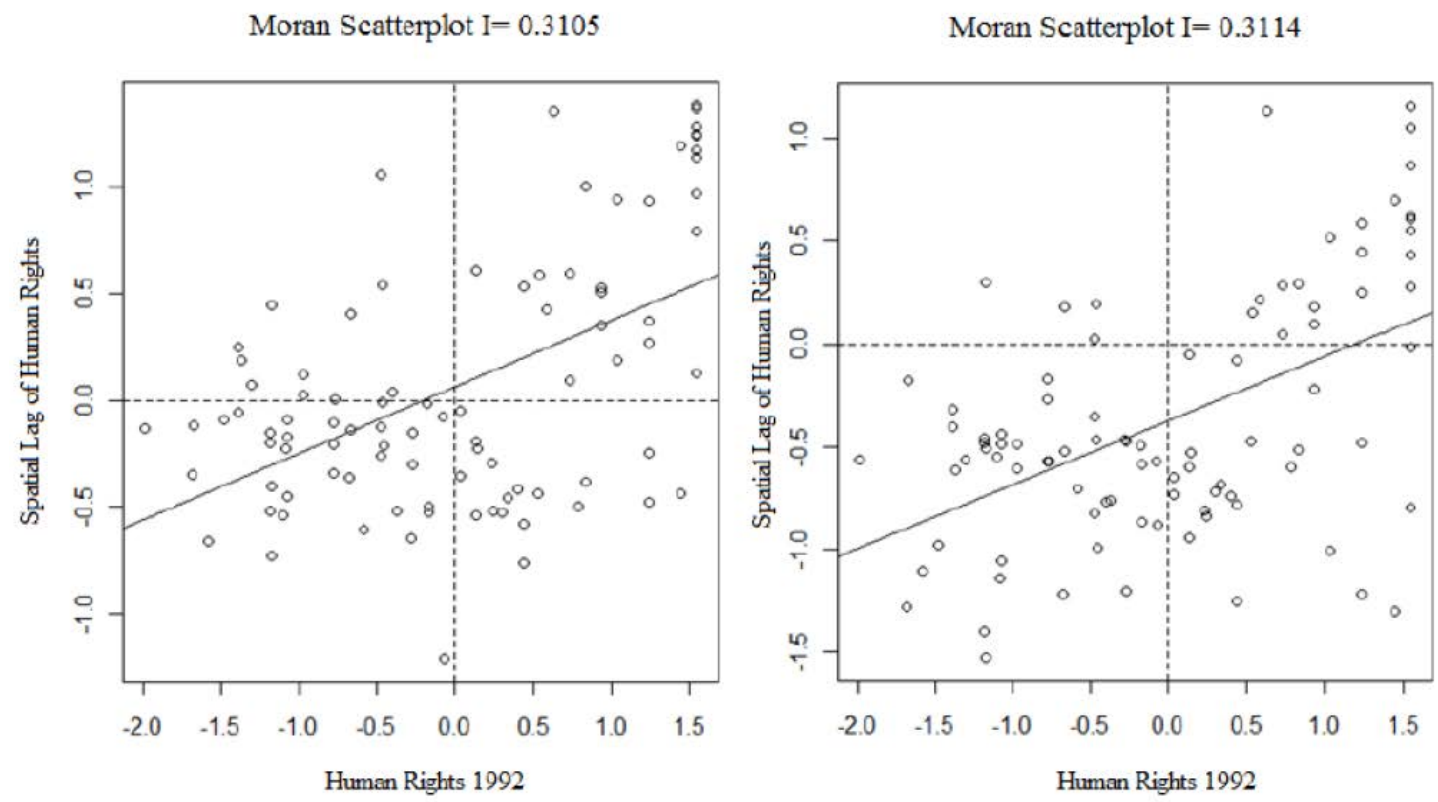

Note: Moran's Scatterplots of Human Rights based upon inverse squared distance and inverse squared distance times relative population 


\section{Appendix 4}

Table 3: Spatial panel regressions with no fixed effects, 1980-2010

\begin{tabular}{|c|c|c|c|c|}
\hline Ihrfactor & Dist1 & Dist2 & Popdist1 & Popdist2 \\
\hline Lnpcgdp & $0.1594 * * *$ & $0.1504 * * *$ & $0.1560 * * *$ & $0.1503 * * *$ \\
\hline Lincineq & $-0.0100 * * *$ & $-0.0054 * * *$ & $-0.0063 * * *$ & -0.0021 \\
\hline Llandineq & $-0.0051 * * *$ & $-0.0059 * * *$ & $-0.0055^{* * *}$ & $-0.0059 * * *$ \\
\hline Domconflict & $-0.1585 * * *$ & $-0.1528 * * *$ & $-0.1604 * * *$ & $-0.1537 * * *$ \\
\hline Catholic & & 0.0001 & & 0.0009 \\
\hline Muslim & & $-0.5364 * * *$ & & $-0.5563 * * *$ \\
\hline W*dep.var. & $0.2190 * * *$ & $0.216955 * * *$ & $0.3070^{* * *}$ & $0.3020^{* * *}$ \\
\hline $\mathrm{n}$ & 2821 & 2821 & 2821 & 2821 \\
\hline R2 & 0.5529 & 0.5913 & 0.5703 & 0.6070 \\
\hline Log likelihood & -3052.1099 & -2925.2367 & -2999.6864 & -2873.4287 \\
\hline \multicolumn{5}{|l|}{$*=$ significant at $10 \%$ level } \\
\hline \multicolumn{5}{|l|}{$* *=$ significant at $5 \%$ level } \\
\hline$* * *=$ signifiacant at $1 \%$ level & & & & \\
\hline
\end{tabular}

Table 4: Spatial panel fixed effects regressions, 1980-2010

\begin{tabular}{lcc}
\hline Dependent Variable ihrfactor & Distfe & Popdistfe \\
\hline lnpcgdp & $0.2139^{* * *}$ & $0.2291^{* * *}$ \\
lincineq & $0.0103^{* * *}$ & $0.0092^{* * *}$ \\
llandineq & $-0.0044^{* * *}$ & $-0.0045^{* * *}$ \\
domconflict & $-0.1074^{* * *}$ & $-0.1074^{* * *}$ \\
W*dep.var. & $0.2610^{* * *}$ & $0.2820^{* * *}$ \\
\hline $\mathrm{n}$ & 2821 & 2821 \\
$\mathrm{R} 2$ & 0.8323 & 0.8315 \\
Log likelihood & -1674.8019 & -1686.0363 \\
LM test for FE & $2754.6159^{* * *}$ & 2627.3003 \\
\hline Ethnic fractionalisation was insignificant and/or unstable. & \\
$*=$ significant at $10 \%$ level & \\
$* *=$ significant at 5\% level & & \\
$* * *=$ signifiacant at $1 \%$ level & & \\
\hline
\end{tabular}

